\title{
Ultrastructure of the Cell Envelope Layers and Surface Details of Legionella pneumophila
}

\author{
By FRANK G. RODGERS ${ }^{1 *}$ AND MICHAEL R. DAVEY ${ }^{2}$ \\ ${ }^{1}$ Department of Microbiology and Public Health Laboratory, University Hospital, Queen's \\ Medical Centre, Nottingham NG7 2UH, U.K. \\ ${ }^{2}$ Department of Botany, University of Nottingham, University Park, Nottingham NG7 2RD, \\ $U . K$.
}

(Received 7 September 1981)

\begin{abstract}
Ten strains representing six serogroups of Legionella pneumophila were examined by electron microscopy using freeze-etching, thin-sectioning and negative-staining techniques. In addition, selected strains were examined further as shadowed and freeze-dried preparations and by scanning electron microscopy. The cell envelope consisted of two membranes, evident in fractured specimens as four short ridges. The major fracture plane was through the inner membrane, and therefore the protoplasmic and extracellular fracture faces of this membrane were predominant. With the exception of one strain (Togus 1), the particle arrangement on these fracture faces was random. A peptidoglycan-like cell wall layer was revealed only in sections of partially plasmolysed cells. Membrane-bounded poly- $\beta$-hydroxybutyrate-like granules were evident in the cytoplasm and these frequently showed plastic deformation due to fracturing. Although appendages were present, the surfaces of organisms and of isolated cell membranes showed no regular arrays of particles.
\end{abstract}

\section{INTRODUCTION}

Legionella pneumophila, a newly recognized bacterial species (Brenner et al., 1979) is the causative agent of Legionnaires' disease, a form of acute lobar pneumonia also known as legionellosis (Fraser et al., 1977; McDade et al., 1977). Identification of the organisms is by immunofluorescence (Cherry et al., 1978) and immunoferritin electron microscopy (Rodgers \& Macrae, 1979; Rodgers, 1982).

Although filamentous forms do occur, the organism, particularly in lung tissues, is present mainly as a short Gram-negative rod approximately $0.5 \mu \mathrm{m}$ wide and 1 to $2 \mu \mathrm{m}$ long. The morphology of the organism has been studied by electron microscopy of negatively stained and thin-sectioned material from post-mortem lung, yolk-sac membranes and bacteriological media (Rodgers et al., 1978; Rodgers, 1979; Chandler et al., 1979). Organisms possessed two membranes enclosing the cytoplasmic contents rich in ribosomes. In vivo, the bacteria undergo both intracellular and extracellular replication by pinching binary fission. In media stimulating rapid growth of legionella species (Feeley et al., 1978; Greaves et al., 1979) flagella have been observed by optical microscopy (Thomason et al., 1979), and flagella and pili by electron microscopy (Rodgers et al., 1979, 1980; Chandler et al., 1980). A characteristic fatty acid profile has been demonstrated for these organisms by gas-liquid chromatography (Moss et al., 1977). Although the presence of peptidoglycan in the cell wall of these bacteria has been disputed, both morphological (Rodgers, 1979; Flesher et al., 1979) and biochemical (Keel et al., 1979; Chandler et al., 1979) evidence suggests that legionella organisms possess a peptidoglycan layer. 
Many Gram-negative organisms have been studied by freeze-etching techniques (Costerton et al., 1974; Glauert et al., 1976), because of the unique views afforded of the structure of the bacterial outer membranes. In this report, we describe the cell envelope structure of $L$. pneumophila as revealed by freeze-etching and thin-sectioning and the surface morphology by negative-staining, shadowing after freeze-drying and scanning electron microscopy.

\section{METHODS}

Organisms and cultivation. Ten strains of $L$. pneumophila representing the six established serogroups were examined by transmission and scanning electron microscopy. The strains were as follows. Serogroup 1: Philadelphia 1 and Philadelphia 2, Pontiac 1, Cambridge 1 and Nottingham N7; serogroup 2: Togus 1; serogroup 3: Bloomington 2; serogroup 4: Los Angeles 1; serogroup 5: Cambridge 2; serogroup 6: Oxford 1. Apart from Bloomington 2 and Oxford 1 , which were of environmental origin, the strains were isolated from clinical material. They were cultivated on enriched blood agar (Greaves et al., 1979) in a $\mathrm{CO}_{2}$ atmosphere for 2 to $3 \mathrm{~d}$. Colonies were fixed in situ for $60 \mathrm{~min}$ by slowly flooding the culture plates with $3 \%(\mathrm{v} / \mathrm{v})$ glutaraldehyde in 0.05 M-cacodylate buffer, $\mathrm{pH} 7.2$, containing $10 \mathrm{~mm}$-magnesium sulphate $(\mathrm{CB})$ followed by three washes with $\mathrm{CB}$ and three with distilled water. In addition, the growth from three culture plates inoculated with each strain was removed with a glass slide, pooled and resuspended in $10 \mathrm{ml}$ Oxoid phosphate-buffered saline (containing $0.15 \mathrm{M}-\mathrm{NaCl}, 2 \mathrm{mM}-\mathrm{KCl}, 8 \mathrm{~mm}-\mathrm{Na}_{2} \mathrm{HPO}_{4}, 1.5 \mathrm{mM}-\mathrm{KH}_{2} \mathrm{PO}_{4}$ ), $\mathrm{pH} 7.4$ (PBS) as thick suspensions for electron microscopy. Each sample was divided, haif being glutaraldehyde fixed and the remainder left unfixed for further study.

Freeze-etching. Fixed specimens, in distilled water or after equilibration for $90 \mathrm{~min}$ in glycerol $(20 \%, \mathrm{v} / \mathrm{v}$ final concentration) were frozen on to $3 \mathrm{~mm}$ diameter collared gold specimen mounts in Freon 22 at its melting point $\left(-155^{\circ} \mathrm{C}\right)$. Freeze-etching was done in a Balzers $360 \mathrm{M}$ unit according to Moor \& Mühlethaler (1963). Samples were etched for $1 \mathrm{~min}$ at $-100^{\circ} \mathrm{C}$, shadowed at $45^{\circ}$ with $2 \mathrm{~nm}$ platinum/carbon (thickness monitored with a QSG 201 quartz crystal) from an electron beam source, and stabilized with a carbon backing film. Replicas were floated off, and cleaned in $5 \%(\mathrm{v} / \mathrm{v})$ hypochlorite in distilled water for $16 \mathrm{~h}$, then thoroughly washed in distilled water and mounted on collodion-coated electron microscope grids. For some freeze-etching studies, the Philadelphia 2, Pontiac 1 and Los Angeles 1 strains were examined as colonies and as suspensions in PBS, both fixed and unfixed. As no structural differences were observed after these different treatments, all subsequent preparations were glutaraldehyde fixed before freezing.

The fracture face nomenclature used is that of Branton et al. (1975), with the protoplasmic face (PF) and extracellular face (EF) modified to include both unit membranes of Gram-negative prokaryotic cells by using the subscripts om for outer membrane and im for inner membrane (plasma membrane).

Freeze-drying and shadowing. A drop of a suspension of fixed organisms in distilled water was added to a collodion-coated grid, excess fluid drained with filter paper and the thin film frozen in Freon 22 before drying. Freeze-drying was done on the cold stage of the Balzers $360 \mathrm{M}$ unit held at $-80^{\circ} \mathrm{C}$ for 30 min under vacuum. Specimens were warmed to $+5^{\circ} \mathrm{C}$ before coating with platinum/carbon as described above. Similar preparations were shadowed after air drying at $22^{\circ} \mathrm{C}$.

Thin-sectioning. After fixation, samples of all strains were washed in CB by centrifugation, and 1 to 2 drops of each concentrated suspension mixed with an equal volume of $2 \%(\mathrm{w} / \mathrm{v})$ molten agarose $\left(<60^{\circ} \mathrm{C}\right)$ and allowed to solidify. The agar pellets were cut into $0.5 \mathrm{~mm}$ cubes and processed for thin-sectioning according to Rodgers (1979).

Negative staining. Bacterial suspensions in distilled water of each of the 10 strains were mixed with an equal volume of $1 \%(\mathrm{w} / \mathrm{v})$ phosphotungstic acid, $\mathrm{pH} 6.5$ (PTA) and applied to Formvar-carbon-coated grids for examination. Cell wall fractions were prepared for negative staining from unfixed samples of Philadelphia 2, Pontiac 1 and Los Angeles 1 strains by freeze-thawing $10 \mathrm{ml}$ bacterial suspension from $-40^{\circ} \mathrm{C}$ followed by blending on an MSE whirlimixer for $30 \mathrm{~min}$ at $+4{ }^{\circ} \mathrm{C}$ in the presence of $15 \mathrm{~g}, 5 \mathrm{~mm}$ diameter Ballotini glass beads.

Scanning electron microscopy. Organisms in suspension were fixed in glutaraldehyde, attached to specimen stubs, critical-point dried and sputter coated as described by Rodgers (1979). In addition, colonies on enriched blood agar were fixed in situ, further prepared for scanning electron microscopy and examined as intact colonies.

Preparation of spheroplasts and cell envelopes. To prepare spheroplasts and isolated cell envelopes, suspensions of Philadelphia 2 and Pontiac 1 strains were made in PBS containing $10 \%(\mathrm{w} / \mathrm{v})$ sucrose, to which EDTA and lysozyme were added, to final concentrations of $1.25 \mathrm{mM}$ and $100 \mu \mathrm{g} \mathrm{ml}^{-1}$, respectively. After incubation for $60 \mathrm{~min}$ at $25^{\circ} \mathrm{C}$ with mixing every $15 \mathrm{~min}$, suspensions were centrifuged at $3000 \mathrm{~g}$ for $20 \mathrm{~min}$ in an MSE Superminor bench centrifuge to give a pellet rich in spheroplasts. The supernatants containing the isolated cell envelope fragments were removed and re-centrifuged at $10000 \mathrm{~g}$ for $15 \mathrm{~min}$ in an MSE Hi-Spin 21 centrifuge. The pellets from each were further prepared for freeze-etching and thin-sectioning. 
All specimens were manipulated in a safety hood, and after preparation were examined in an AEI Corinth 500 , Jeol 100C Temscan, AEI EM6B or Jeol 100S electron microscope.

\section{RES ULTS}

Freeze-etching of L. pneumophila colonies fixed in situ showed close aggregates of micro-organisms in longitudinal and transverse arrangement to the plane of fracture (Fig. $1 a$ ). In these colonies, bacterial cells more than $20 \mu \mathrm{m}$ in length were common (Fig. $1 b$ ). The major fracture plane occurred through the hydrophobic region of the plasma (inner) membrane revealing both the protoplasmic $\left(\mathrm{PF}_{\mathrm{im}}\right)$ and extracellular $\left(\mathrm{EF}_{\mathrm{im}}\right)$ faces (Fig. 1c), the $\mathrm{PF}_{\mathrm{im}}$ being seen more often. For each strain studied, the distribution of particles on both the $\mathrm{PF}_{\mathrm{im}}$ and $\mathrm{EF}_{\mathrm{im}}$ was unaffected by the preparation method, and was similar in unfixed, glutaraldehyde-fixed and glutaraldehyde-fixed/glycerol cryo-protected cells. However, in the cryo-protected specimens, the fracture plane passed through the cell envelope at a point level with the fracture plane of the surrounding eutectic to a much higher frequency than in preparations without glycerol. The effect of this was to remove from organisms large areas of either the outer membrane together with the outer leaf of the inner membrane, so revealing large proportions of the $\mathrm{PF}_{\mathrm{im}}$, or the cytoplasmic contents, exposing large areas of the $\mathrm{EF}_{\mathrm{Im}}$ (Fig. 1c).

With the exception of Togus 1 (serogroup 2), all strains of L. pneumophila showed the $\mathrm{PF}_{\mathrm{im}}$ covered with numerous randomly arranged intra-membraneous particles. The $\mathrm{EF}_{\mathrm{im}}$ of the bacteria had similar randomly arranged particles but they were fewer in number (Fig. $1 c$ ). At the poles of cells, the particles were occasionally arranged in small circular groups; they may be related to the presence of appendages or cytoplasmic vesicles or mesosome formation. In transverse fractures, the bacteria were bounded by two pronounced ridges (Fig. $1 d$ ), corresponding to the outer and inner membranes, with no sub-structure evident. The outer membrane had a weak fracture plane, and was seen only as edges at the poles of cells (Fig. 1e). Consequently the particle distribution on the $\mathrm{EF}_{\mathrm{om}}$ or the complementary $\mathrm{PF}_{\mathrm{om}}$ were not observed. In concave view from within cells, the outer membrane appeared as a single layer beneath the $\mathrm{EF}_{\text {im }}$ (Fig. $1 f$ ).

Fracture and etching of specimens in the absence of cryo-protectant revealed the outer surface of legionellae to be smooth, with a limited number of irregular roughly spherical 10 to $30 \mathrm{~nm}$ diameter granules, often in pairs. Although these occurred on both unfixed and glutaraldehyde-fixed material, they were more frequently observed in the unfixed specimens (Fig. $2 a$ ). Flagella, which had a distinctly striated or helical structure, were seen in all preparations without glycerine treatment (Fig. $2 b$ ). Spherical bodies up to $0.5 \mu \mathrm{m}$ in diameter, resembling poly- $\beta$-hydroxybutyrate granules, were present in the cytoplasm (Fig. $2 c$ ). These were often, but not invariably, membrane-bounded. Those granules whose contents were removed in fracturing showed a raised edge round their circumference, protruding from the etched plane of the cytoplasm (Fig. $2 c$ ). The cores of some granules were stretched out of the plane of fracture by up to $1.25 \mu \mathrm{M}$, as a result of deformation. The stretched cores were surrounded by a region of the granule showing converging 'stretch lines' (Fig. $2 d$ ).

The organization of the intramembraneous particles on the $\mathrm{PF}_{\mathrm{im}}$ of the Togus 1 (serogroup 2) strain differed from that found in other strains. In Togus 1 , the particles were not randomly arranged, but occurred in the majority of cells in discrete rows one to three particles in width (Fig. $3 a$ ). Other cells had particles in close-packed random formations separated by clear particle-free zones (Fig. $3 b$ ). The particle arrangement on the $\mathrm{EF}_{\mathrm{im}}$ of this strain, however, was random as for other strains.

Thin sections of all strains, both as colonies fixed in situ and as suspensions, confirmed the results of freeze-etching studies. Organisms had the morphology of Gram-negative rods approximately $0.6 \mu \mathrm{m}$ in width, of variable length, and surrounded by two unit membranes. 

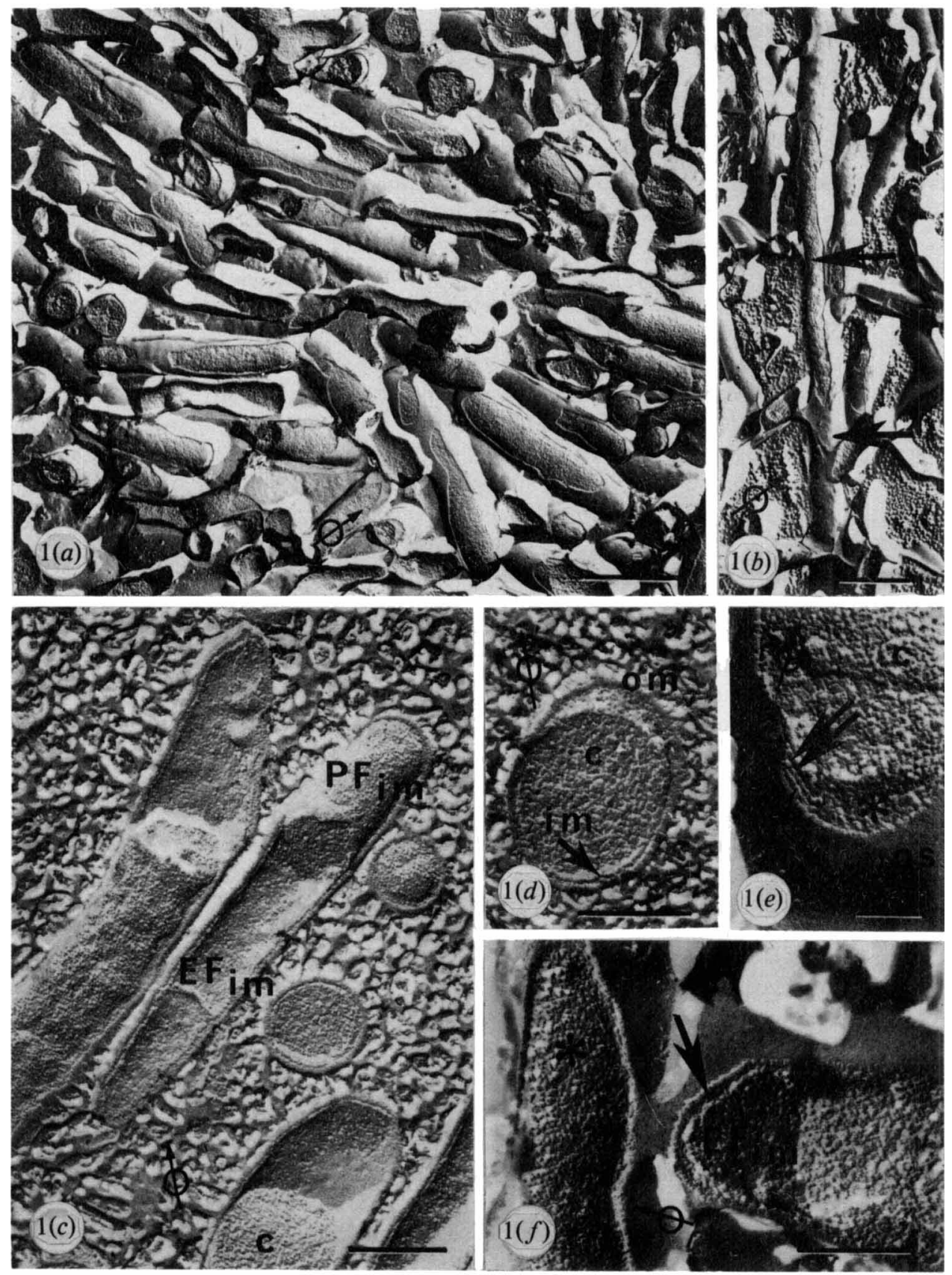

Fig. 1. Electron micrographs of freeze-etched L. pneumophila. (a) Los Angeles 1; (b) Nottingham N7; $(c-f)$ Philadelphia 2. (a) Organisms in a colony in close aggregation. The colony was fixed in glutaraldehyde without glycerol and shows bacteria in longitudinal and transverse arrays. (b) Organism more than $10 \mu \mathrm{m}$ in length (arrows). The bar markers in (a) and (b) represent $1 \mu \mathrm{m}$. (c) Organisms in suspension, glutaraldehyde fixed and glycerol cryo-protected. Note the random distribution of intra-membraneous particles on the $\mathrm{PF}_{\mathrm{im}}$ and $\mathrm{EF}_{\mathrm{im}}$, the major fracture plane. The cytoplasm (c) is evident. (d) A single bacterium in transverse fracture. Note the cytoplasm (c), the outer membrane (om) and inner membrane (im). The bar markers in $(c)$ and $(d)$ represent $0.25 \mu \mathrm{m}$. (e) An oblique fracture showing the four fracture faces of the two unit membranes; the two outer membrane faces (short 

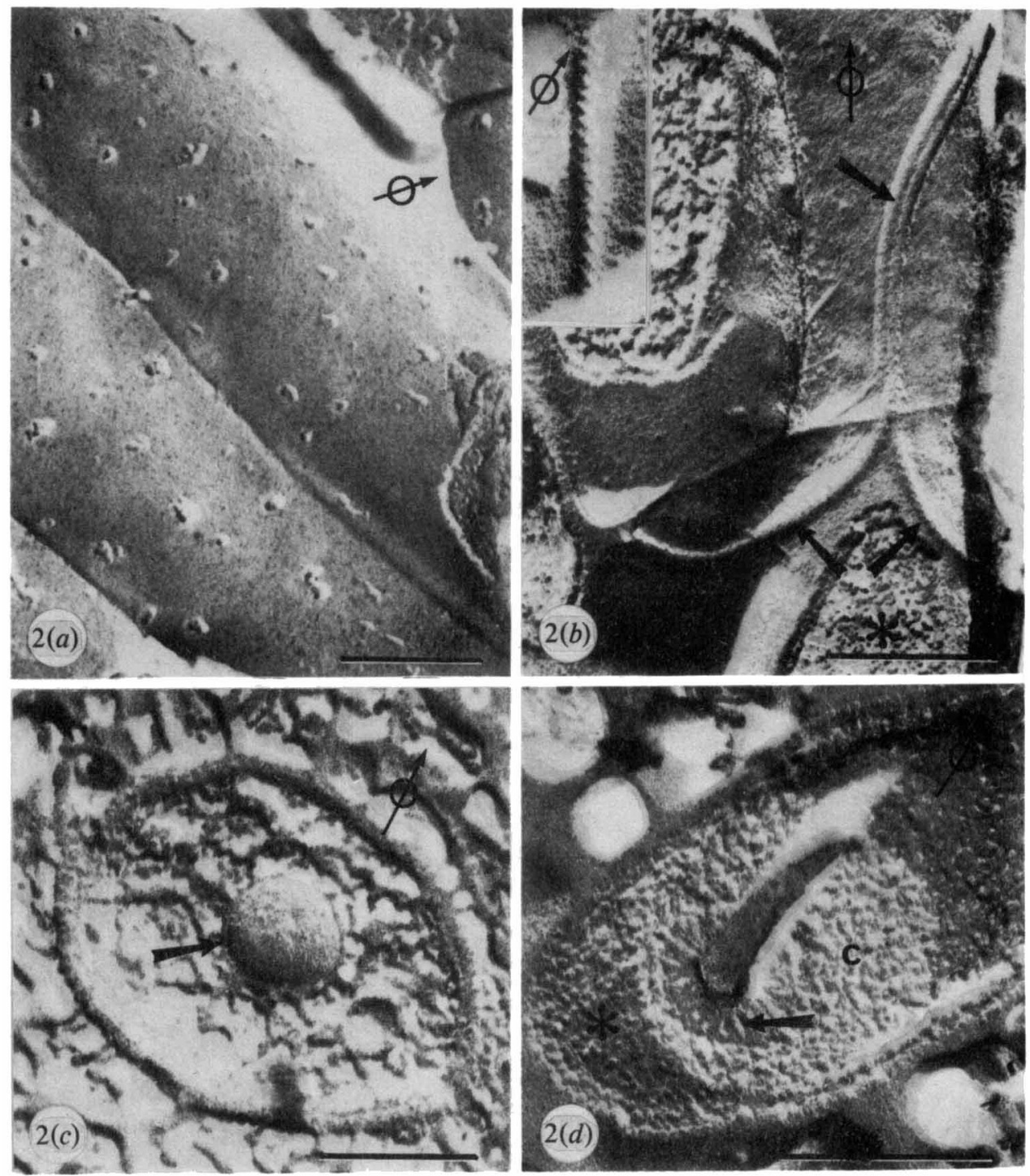

(continued from facing page)

arrows), and the two inner membrane faces (long arrows) are evident, with the outer surface (os) and the protoplasmic fracture face of the inner membrane $\left(\mathrm{PF}_{\mathrm{im}}, *\right)$ predominating. The bar marker represents $50 \mathrm{~nm}$. $(f)$ Micrograph showing the extracellular fracture face of the inner (plasma) membrane $\left(\mathrm{EF}_{\mathrm{im}}\right)$ with the inner surface of the outer membrane lying beneath (arrow). The protoplasmic face of the inner (plasma) membrane $\left(\mathrm{PF}_{\mathrm{im}}, *\right)$ can be seen in an adjacent cell. The bar marker represents $0.25 \mu \mathrm{m}$. The arrows with circles indicate the direction of shadowing.

Fig. 2. Electron micrographs of freeze-etched L. pneumophila. $(a),(c)$ and $(d)$ Philadelphia $2 ;(b)$ and inset Togus 1. (a) The outer surface of four adjacent bacteria showing scattered, roughly spherical granules. The bar marker represents $0.25 \mu \mathrm{m}$. (b) Two flagella (arrows) on the outer surface of adjacent bacteria. The protoplasmic face of the inner (plasma) membrane $\left(\mathrm{PF}_{\mathrm{im}}, *\right)$ is evident. The bar marker represents $0.3 \mu \mathrm{m}$. Inset: a single flagellum with a helical structure. For the inset the bar marker represents $0.2 \mu \mathrm{m}$. (c) A spherical poly- $\beta$-hydroxybutyrate-like granule in convex view. Note the smooth contents and limiting 'membrane' (arrow). The contents of the adjacent granule have been removed in fracture, and the 'membrane' appears as a single ridge protruding from the cytoplasm. The bar marker represent $0.5 \mu \mathrm{m}$. (d) A granule whose contents have been stretched out of the plane of fracture due to plastic deformation. Stretch lines (arrow) surround the base of the extended core. The cytoplasm (c) and the protoplasmic face of the plasma (inner) membrane $\left(\mathrm{PF}_{\mathrm{im}}, *\right)$ are illustrated. The bar marker represents $0.5 \mu \mathrm{m}$. The arrows with circles indicate the direction of shadowing. 

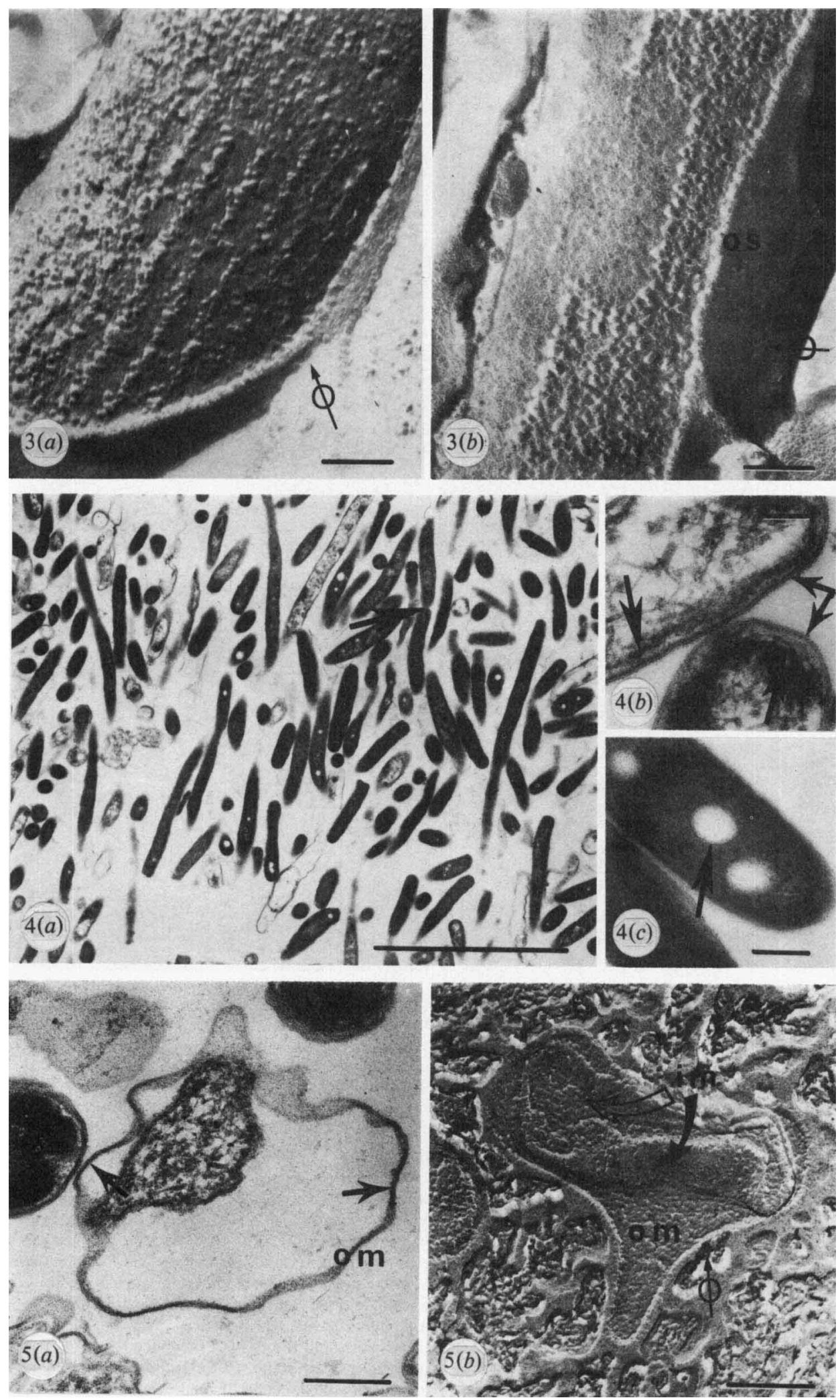
The cytoplasm contained numerous ribosomes and dispersed fine thread-like nuclear elements (Fig. $4 a$ ). Division was by pinching binary fission. An electron-dense peptidoglycan-like layer between the inner and outer membranes was evident only in partially plasmolysed cells (Fig. $4 b$ ). The poly- $\beta$-hydroxybutyrate-like granules seen in the cytoplasm (Fig. $4 c$ ) were unstructured and electron translucent, due presumably to the partial extraction of the lipid during the embedding process; a limiting membrane was usually not detected.

In thin sections of isolated cell walls prepared by either physical disruption or lysozyme treatment, the unit membrane structure of the outer membrane (OM) was clear; the membrane had an average width of $10 \mathrm{~nm}$. Similar findings were made for the plasma membrane (PM) surrounding spheroplasts. However, amorphous material, presumably derived from the intermediate layer between the two unit membranes, was often associated with the inner surfaces of the outer membrane fragments, extending their width to $15 \mathrm{~nm}$. (Fig. 5a). A dense layer resembling peptidoglycan was not observed attached to membrane fragments. Freeze-etching of these preparations gave results similar to those with sectioned material, and no additional layers were detected. Organisms treated with lysozyme showed a widening of the gap between the inner and outer membranes (Fig. $5 b$ ), due to the action of the enzyme on the intermediate layer. This was not evident in freeze-etched cells not exposed to lysozyme.

Negatively stained organisms were rod shaped and up to $2 \mu \mathrm{m}$ long, with tapered ends (Fig. $6 a$ ). The bacterial surfaces were either electron opaque and evenly convoluted or ruffled, or electron translucent and smooth, with poly- $\beta$-hydroxybutyrate-like granules evident in the translucent organisms (Fig. 6b). Negatively stained isolated cell walls, prepared by physical or lysozyme disruption were morphologically similar and appeared as smooth translucent membraneous material with no evidence of an outermost additional layer or regular array of surface particles (Fig. $6 c$ ). Electron microscopy of metal-shadowed air-dried or frozen-dried cells showed smooth or ruffled cell surfaces without evidence of a structured cell surface layer. Similar results were obtained with negatively stained whole cells. Evaginations or 'blebs' were observed on the surface of organisms of many strains by scanning electron microscopy, particularly when examined as intact colonies (Fig. 6e). Similar 'blebs' had been seen frequently on organisms in formalin-fixed suspensions of post-mortem lung tissues from clinical Legionnaires' disease. The convoluted surface details present in intact cells were not

Fig. 3. Electron micrographs of the $\mathrm{PF}_{\mathrm{im}}$ of freeze-etched Togus 1 strain. (a) Intra-membraneous particles arranged in rows one to three particles in width. (b) Intra-membraneous particles in close-packed arrangement, interspersed with particle-free areas. The outer surface (os) of organisms can be seen. The bar markers represent $0.1 \mu \mathrm{m}$. The arrows with circles indicate the direction of shadowing.

Fig. 4. Electron micrographs of Philadelphia 2 strain in thin section, stained with uranyl acetate and lead citrate. (a) Organisms in diverse orientation to the plane of section. Variation in the length, width, cytoplasmic density and degree of vacuolation are apparent, along with pinching non-septate division (arrow). The bar marker represents $5 \mu \mathrm{m}$. (b) Partially plasmolysed organisms showing outer membranes (short arrows), inner (plasma) membranes (long arrows) and dense material within the inter-membrane spaces. Fine thread-like nuclear elements are also evident. The bar marker represents $0.1 \mu \mathrm{m}$. (c) Spherical granules are present in the cytoplasm. Note the limiting 'membrane' (arrow) within which lies an electron-lucent core, surrounded by diffusely staining material. The bar marker represents $0.2 \mu \mathrm{m}$.

Fig. 5. Electron micrographs of Philadelphia 2 organisms treated with lysozyme and EDTA. (a) A thin-sectioned organism shows a detached outer membrane (om), with adhering amorphous material (arrows) and a cell fragment with surrounding inner (plasma) membrane. (b) Freeze-fractured organism showing the inner face of the outer membrane (om), the outer face of the inner (plasma) membrane (im. filled arrow) and the inner face of the inner membrane (im, open arrow). The bar markers represent $0.25 \mu \mathrm{m}$. The arrow with circle indicates the direction of shadowing. 

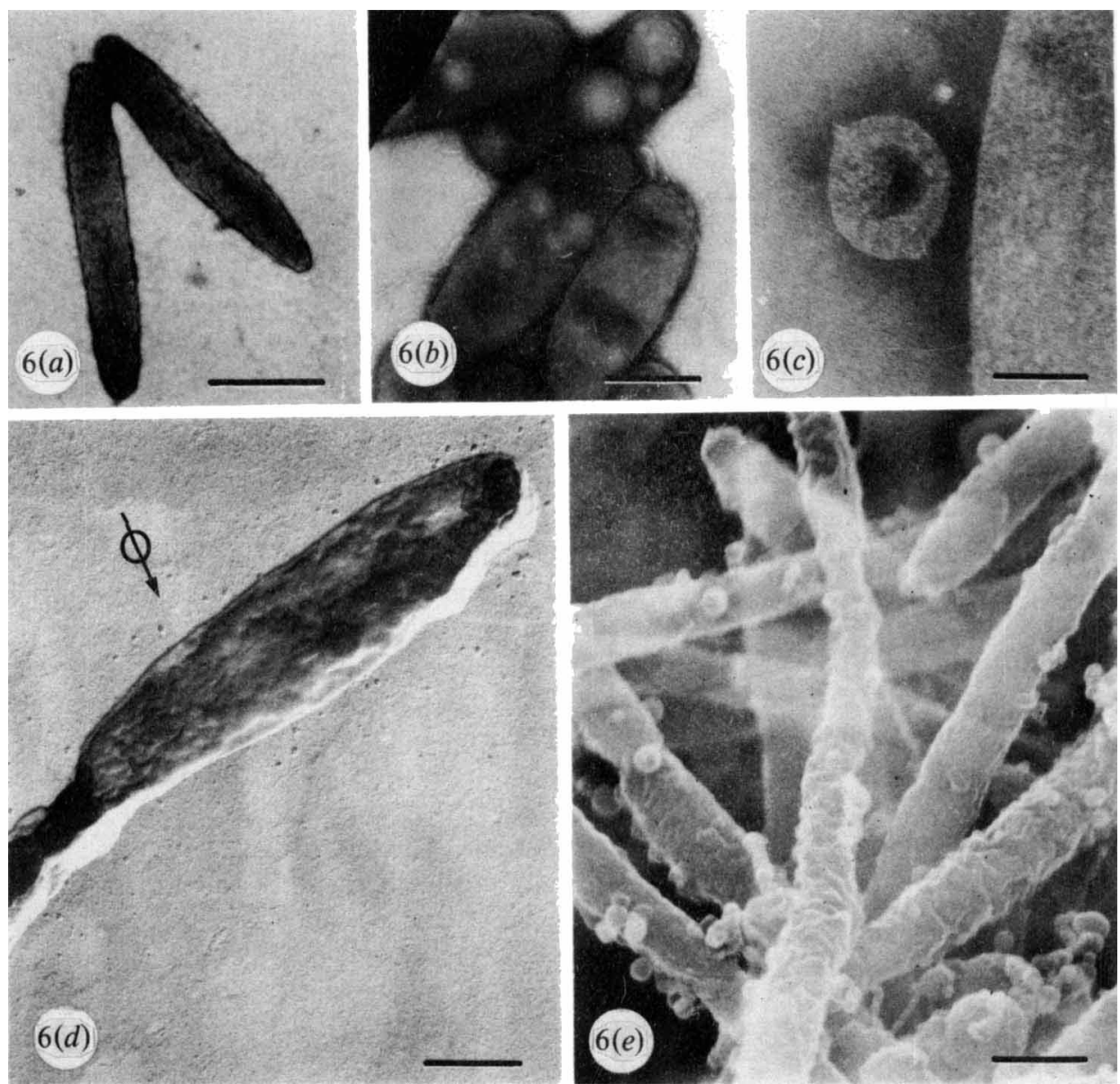

Fig. 6. (a) Bloomington 2 organisms negatively stained with $1 \%$ PTA, showing tapered ends and convoluted surfaces. The bar marker represents $1 \mu \mathrm{m}$. (b) Nottingham N7 smooth-surfaced organisms with poly- $\beta$-hydroxybutyrate-like granules of various sizes. Pili are also evident. Negatively stained with $1 \%$ PTA. The bar marker represents $0.5 \mu \mathrm{m}$. (c) Isolated outer membrane of a Pontiac 1 organism showing no regular arrays or surface details. Negatively stained with $1 \%$ PTA. The bar marker represents $0.1 \mu \mathrm{m}$. $(d)$ Freeze-dried. shadowed Philadelphia 1 organism with ruffled surface and no sub-unit structure. The bar marker represents $0.5 \mu \mathrm{m}$. The arrow with circle indicates the direction of shadowing. (e) Organisms in a colony of the Cambridge 1 strain sputter-coated with gold and examined by scanning electron microscopy. 'Blebs' are evident on many organisms. The bar marker represents $0.5 \mu \mathrm{m}$.

seen in isolated outer membranes, irrespective of the method of preparation. Flagella were observed on all strains, irrespective of preparation method, but pili were clearly revealed only by negative staining.

\section{DISCUSSION}

The cell envelope layers of $L$. pneumophila, as revealed in thin sections and by freeze-etch techniques, resembled those described for many other Gram-negative bacteria (Costerton et al., 1974; Glauert et al., 1976). The planes and ridges seen in freeze-fractured organisms appeared to correspond with the layers seen in thin sections, and comprised two unit membranes with, in the intervening space, evidence of amorphous material which may have been peptidoglycan (Rodgers, 1979; Flesher et al., 1979; Chandler et al., 1979). The 10 strains of $L$. pneumophila studied were similar in these respects. 
In the absence of glycerol, both fixed and unfixed legionella organisms fractured through the hydrophobic region of the inner (plasma) membranes only. Similar findings have been made for Acinetobacter (Sleytr et al., 1974). In contrast are the observations of Every \& Skerman (1980), who showed that the inner and outer membranes of Bacteroides nodosus fractured with equal frequency, revealing the internal particle arrangements for both these membranes. Sleytr et al. (1974) could reveal the intra-membrane particle distribution of the outer membrane only by the addition of glycerol to unfixed specimens. The use of glycerol without fixation induced the rearrangement of intra-membrane particles in freeze-etched animal cells (McIntyre et al., 1974), plant protoplasts (Davey \& Mathias, 1980), cells of Entamoeba hystolytica (Martinez-Palomo et al., 1976) and Escherichia coli (Arancia et al., 1980). It is therefore difficult to interpret some of the structures and particle arrangements reported on the fracture faces of the outer membranes of glycerol-treated unfixed Gram-negative organisms. Arancia et al. (1980) showed that fixation with glutaraldehyde and subsequent glycerol cryo-protection resulted in relatively artefact-free preparations of $E$. coli. In the present study on legionellae, cryo-protection was used only after glutaraldehyde fixation, and this effected a weak fracture in the hydrophobic region of the outer membrane of the bacteria; the outer membrane then appeared as two short ridges, too small for particle arrangements to be assessed. The intra-membrane particle arrangement on the $\mathrm{PF}_{\mathrm{im}}$ and $E F_{i m}$ of all strains except Togus 1 (serogroup 2) were random. It is not clear why the particles on the $\mathrm{PF}_{\mathrm{im}}$ of a large proportion of organisms of this strain should occur in short straight chains with large clear spaces between. Temperature fluctuations during preparation are known to induce particle rearrangements (Arancia et al., 1980); however, all the strains we studied were prepared in an identical manner. Lounatmaa (1979) observed similar particle-free zones on the $\mathrm{PF}_{\mathrm{om}}$ of Salmonella typhimurium mutants lacking a major outer membrane protein. It cannot be excluded that the strain of Togus 1 used in this study lacked a major protein from the inner membrane.

Due to the lack of lipid in peptidoglycan, this layer did not provide a cleavage plane, but was associated with the inner leaf of the outer membrane, which appeared as a much thickened ridge similar in appearance to that observed in Acinetobacter (Sleytr et al., 1974). In thin sections, the peptidoglycan-like layer resembled that present in aquatic pseudomonads (Costerton et al., 1974; Costerton, 1979), being observed only after partial plasmolysis. Biochemical evidence for the existence of this layer has also been reported (Chandler et al., 1979).

Failure to observe an extracellular capsule on any strain agrees with the finding of Rodgers (1979). Indeed, apart from the presence of striated flagella, surfaces of legionella organisms were smooth. A layer of sub-units on the outer membrane surface reported for many Gram-negative bacteria (Glauert et al., 1976), and in particular for those of aquatic origin (Costerton et al., 1974) was not present, in spite of the aquatic habitat of many strains of $L$. pneumophila (Blackmon et al., 1981). The 'blebs' seen on the surface of freeze-etched legionella organisms may be condensed pili-related proteins, or random structural proteins of the outer membranes as proposed in the membrane model of Costerton et al. (1974).

The poly- $\beta$-hydroxybutyrate-like granules were bounded by a limiting membrane seen as a single ridge with no fracture planes after freeze-etching and as a single layer in thin sections. The contents of the granules, which appeared unstructured by negative stain and thin-section, were subject to plastic deformation in fracture with the central core pulled out and the surrounding region stretched radially to the centre, suggesting that they consist of two concentric regions of different consistency surrounded by a single layer or 'membrane'. In this respect the granules of $L$. pneumophila resemble those of the Gram-positive Bacillus species (Dunlop \& Robards, 1973; Sleytr \& Robards, 1977).

The ability of legionellae to infect human cells in vivo (Rodgers et al., 1978; Rodgers, 1979) and in vitro (Wong et al., 1980) is a characteristic shared with only a few bacterial species. Although the underlying mechanisms are unknown, the structure and antigenicity of 
the cell envelope are no doubt important. Biochemical analysis of purified cell wall sub-fractions coupled with specific immune labelling in freeze-fracture and thin-section electron microscopy are required to determine the nature of the outer coat of legionellae and to evaluate their role in the pathogenic process and the subsequent immune response of the host.

We thank Mrs Joan Casson for help in printing the electron micrographs.

\section{REFERENCES}

Arancia, G., Rosati, V. \& Trovalusci Cateri, P. (1980). Effects of glutaraldehyde and glycerol on freeze-fractured Escherichia coli. Journal of Microscopy 118, 161-176.

Blackmon, J. A., Chandler, F. W., Cherry, W. B., England, A. C., Feeley, J. C., Hicklin, M. D., MCKinNey, R. M. \& Wilkinson, H. W. (1981). Legionellosis. American Journal of Pathology 103, 427-465.

Branton, D., Bullivant, S., Gilula, N. B., KARNovsky, M. J., MoOR, H., MÜHLETHAler, K., Northcote, D. H., Packer, L., Satir, B., Satir, P., Speth, V., Staehlin, L. A., Steere, R. L. \& Weinstein, R. S. (1975). Freeze-etching nomenclature. Science 190, 54-56.

Brenner, D. J., Steigerwalt, A. G. \& McDade, J. E. (1979). Classification of the Legionnaires' disease bacterium: Legionella pneumophila, genus novum, species nova, of the family Legionellaceae, familia nova. Annals of Internal Medicine 90, 656658.

Chandler, F. W., Cole, R. M., Hicklin, M. D., Blackmon, J. A. \& Callaway, C. S. (1979). Ultrastructure of the Legionnaires' disease bacterium. A study using transmission electron microscopy. Annals of Internal Medicine 90, 642-647.

Chandler, F. W., Roth, I. L., Callaway, C. S., Bump, J. L., Thomason, B. M. \& Weaver, R. E. (1980). Flagella on Legionnaires' disease bacteria. Ultrastructural observations. Annals of Internal Medicine 93, 711-714.

Cherry, W. B., Pitman, B., Harris, P. P., Hebert, G. A., Thomason, B. M., Thacker, L. \& Weaver, R. E. (1978). Detection of Legionnaires' disease bacteria by direct immunofluorescent staining. Journal of Clinical Microbiology 8, 329-338.

Costerton, J. W. (1979). The role of electron microscopy in the elucidation of bacterial structure and function. Annual Review of Microbiology 33, 459-479.

Costerton, J. W., Ingram, J. M. \& Cheng, K-J. (1974). Structure and function of the cell envelope of Gram-negative bacteria. Bacteriological Reviews 38, 86-110.

Davey, M. R. \& Mathias, R. J. (1979). Closepacking of plasma membrane particles during wall regeneration by isolated higher plant protoplasts fact or artefact. Protoplasma 100, 85-99.

Dunlop, W. F. \& Robards, A. W. (1973). Ultrastructural study of poly- $\beta$-hydroxybutyrate granules from Bacillus cereus. Journal of Bacteriology 141, 1271-1280.

Every, D. \& Skerman, T. M. (1980). Ultrastructure of the Bacteroides nodosus cell envelope layers and surface. Journal of Bacteriology 141, 845-857.

Feeley, J. C., Gorman, G. W. \& Gibson, R. J. (1978). Primary isolation media and methods. In 'Legionnaires' the Disease, the Bacterium and the Methodology, pp. 107-117. Edited by G. L. Jones \& G. A. Hebert. Atlanta, Georgia: Center for Disease Control.

Flesher, A. R., Susumu, I., Mansheim, B. J. \& Kaspar, D. L. (1979). The cell envelope of the Legionnaires' disease bacterium. Annals of Internal Medicine 90, 628-630.

Fraser, D. W., Tsai, T. R., Orenstein, W., Parkin, W. E., Beecham, H. J., Sharrar, R. G., HaRris, J., Mallison, G. F., Martin, S. M., McDade, J. E., Shepard, C. C., Brackman, P. S., \& THE Field Investigation Team (1977). Legionnaires' disease, description of an epidemic of pneumonia. New England Journal of Medicine 297, 1189-1197.

Glauert, A. M., Thornley, M. J., Thorne, K. J. I. \& SLEYTR, U. B. (1976). The surface structure of bacteria. In Microbial Ultrastructure, the Use of the Electron Microscope, pp. 31-47. Edited by R. Fuller \& D. W. Lovelock. London: Academic Press.

Greaves, P. W., Sharp, G. B. \& Macrae, A. D. (1979). Isolation of Legionella pneumophila. Lancet 1, 551-552.

Keel, J. A., Finnerty, W. R. \& Feeley, J. C. (1979). Fine structure of the Legionnaires' disease bacterium: in vitro and in vivo studies of four isolates. Annals of Internal Medicine 90, 652-655.

LounAtMAA, K. (1979). Ultrastructure of the outer membrane of Salmonella typhimurium bacteriocinresistant mutants deficient in the $33 \mathrm{~K}$ protein. Journal of Bacteriology 139, 646-651.

Martinez-Palomo, A., Pinto da Silva, P. \& Chavez, R. (1976). Membrane structure of Entamoeba histolytica: fine structure of freezefractured membranes. Journal of Ultrastructural Research 54, 148-158.

McDade, J. E., Shepard, C. C., Fraser, D. W., TSAI, T. R., Redus, M. A., Dowdle, W. R. \& THE LABORATORY INVESTIGATION TEAM. (1977). Legionnaires' disease: isolation of a bacterium and demonstration of its role in other respiratory disease. New England Journal of Medicine 297, 1197-1203.

Mcintyre, J. A., Gilula, N. B. \& Karnovsky, M. J. (1974). Cryoprotectant induced redistribution of intramembrane particles in mouse lymphocytes. Journal of Cell Biology 60, 192-203.

Moor, H. \& Mühlethaler, K. (1963). Fine structure of frozen etched yeast cells. Journal of Cell Biology 17, 609-629. 
Moss, C. W., Weaver, R. E., Dees, S. B. \& Cherry, W. B. (1977). Cellular fatty acid composition of isolates from Legionnaires' disease. Journal of Clinical Microbiology 6, 140-143.

RoDGERS, F. G. (1979). Ultrastructure of Legionella pneumophila. Journal of Clinical Pathology 32, 1195-1202.

RODGERS, F. G. (1982). Identification of Legionella pneumophila antigens and antibodies by immunoferritin electron microscopy. Journal of Medical Microbiology 15, 181-187.

Rodgers, F. G. \& Macrae, A. D. (1979). Immunoferritin electron microscopy in legionellosis. Lancet 1, 786.

Rodgers, F. G., Macrae, A. D. \& Lewis, M. J. (1978). Electron microscopy of the organism of Legionnaires' disease. Nature, London 272, 825826.

Rodgers. F. G., Greaves, P. W. \& Macrae, A. D. (1979). Flagella and fimbriae on legionella organisms. Lancet 2, 753-754.
Rodgers, F. G., Greaves, P. W., Macrae, A. D. \& LEWIS, M. J. (1980). Electron microscopic evidence of flagella and pili on Legionella pneumophila. Journal of Clinical Pathology 33, 1184-1188.

Sleytr, U. B. \& Robards, A. W. (1977). Plastic deformation during freeze-cleavage: a review. Journal of Microscopy 110, 1-25.

Sleytr, U. B.. Thornley, M. J. \& Glauert, A. M. (1974). Location of the fracture faces within the cell envelope of Acinetobacter species strain MJT/F5/5. Journal of Bacteriology 118, 693-707.

Thomason, B. M., Chandler, F. W. \& Hollis, D. G. (1979). Flagella on Legionnaires' disease bacteria: an interim report. Annals of Internal Medicine 91, 224-226.

Wong, M. C., Ewing, E. P., Callaway, C. S. \& PEACOCK, W. L. (1980). Intracellular multiplication of Legionella pneumophila in cultured human embryonic lung fibroblasts. Infection and Immunity 28. 1014-1018. 